\title{
Poly(ester-urethane) scaffolds: effect of structure on properties and osteogenic activity of stem cells
}

\author{
Aysel Kiziltay ${ }^{1,2,3}$, Angel Marcos-Fernandez ${ }^{6}$, Julio San Roman ${ }^{6}$, Rui A. Sousa ${ }^{7,8}$, Rui L. Reis ${ }^{7,8}$, \\ Vasif Hasirci $^{1,2,4}$ and Nesrin Hasirci ${ }^{1,2,5 *}$ \\ ${ }^{1}$ BIOMATEN-Centre of Excellence in Biomaterials and Tissue Engineering, Middle East Technical University (METU), Ankara, Turkey \\ ${ }^{2}$ Graduate Department of Biotechnology, Middle East Technical University (METU), Ankara, Turkey \\ ${ }^{3}$ Central Laboratory, Middle East Technical University (METU), Ankara, Turkey \\ ${ }^{4}$ Department of Biological Sciences, Middle East Technical University (METU), Ankara, Turkey \\ ${ }^{5}$ Department of Chemistry, Middle East Technical University (METU), Ankara, Turkey \\ ${ }^{6}$ Instituto de Ciencia y Tecnología de Polímeros (CSIC), Madrid, Spain \\ ${ }^{7}$ 3Bs Research Group - Biomaterials, Biodegradables and Biomimetics, Universidade do Minho, Headquarters of the European Institute of \\ Excellence on Tissue Engineering and Regenerative Medicine, Taipas, Guimarães, Portugal \\ ${ }^{8}$ ICVS/3Bs PT Government Associated Laboratory, Braga, Guimarães, Portugal
}

\begin{abstract}
The present study aimed to investigate the effect of structure (design and porosity) on the matrix stiffness and osteogenic activity of stem cells cultured on poly(ester-urethane) (PEU) scaffolds. Different three-dimensional (3D) forms of scaffold were prepared from lysine-based PEU using traditional salt-leaching and advanced bioplotting techniques. The resulting scaffolds were characterized by differential scanning calorimetry (DSC), thermogravimetric analysis (TGA), scanning electron microscopy (SEM), mercury porosimetry and mechanical testing. The scaffolds had various pore sizes with different designs, and all were thermally stable up to $300^{\circ} \mathrm{C}$. In vitro tests, carried out using rat bone marrow stem cells (BMSCs) for bone tissue engineering, demonstrated better viability and higher cell proliferation on bioplotted scaffolds compared to salt-leached ones, most probably due to their larger and interconnected pores and stiffer nature, as shown by higher compressive moduli, which were measured by compression testing. Similarly, SEM, von Kossa staining and EDX analyses indicated higher amounts of calcium deposition on bioplotted scaffolds during cell culture. It was concluded that the design with larger interconnected porosity and stiffness has an effect on the osteogenic activity of the stem cells. Copyright (C) 2013 John Wiley \& Sons, Ltd.
\end{abstract}

Received 25 May 2012; Revised 13 June 2013; Accepted 7 October 2013

Keywords poly(ester-urethane); scaffold; stiffness; porosity; bone marrow stem cells; osteogenic activity

\section{Introduction}

Bone tissue engineering (BTE) is a promising alternative strategy for healing severe bone defects, utilizing cell-loaded scaffolds with engineering principles. A proper interaction between the loaded cells and the porous scaffold is important for the success of the implantable device. Various synthetic or natural materials, such as ceramics or polymers, are tested for their ability to support cell adhesion, proliferation and differentiation. Generally, natural polymers have better

\footnotetext{
*Correspondence to: Nesrin Hasirci, Middle East Technical University, Department of Chemistry, 06800 Ankara, Turkey. E-mail: nhasirci@metu.edu.tr
}

compatibility but may not have the desired strength, while the synthetic ones offer some advantages, such as controllable physical, chemical, surface and degradation properties. They can be easily designed to form porous three-dimensional (3D) complex structures with high porosity and a high surface area, which are essential for anchorage-dependent cells, such as bone cells, to attach, survive and differentiate (Rada et al., 2012). The role of a scaffold is to act as a temporary extracellular matrix (ECM) for the regenerating cells. Thus, the success of tissue engineering is greatly determined by the properties of the scaffolds and their in vitro and in vivo behaviours. Many parameters, such as shape, chemistry, surface roughness and surface energy, as well as pore size and mechanical strength, affect the cell response. Cells can sense and respond to external forces 
exerted by the surrounding fluid (Kasper et al., 2008) or by the stiffness of the substrate (Discher et al., 2005), and these forces have roles in cell adhesion, locomotion, growth and differentiation (Wagoner et al., 2011). Pelham and Wang (1997) developed polyacrylamide-based matrices having identical chemistry but different flexibility and showed that differences in substrate flexibility led to changes in adhesion structures and motility of epithelial and fibroblast cells; with a faster migration rate of fibroblasts and elevated lamellipodial protrusion-retraction activities in epithelial cells. It is reported in the literature that motor neurons derived from embryonic mouse spinal cord prefer soft surfaces to on which extend branches rather than hard surfaces (Flanagan et al., 2002) but, contrarily, fibroblasts spread well on hard surfaces while having a round shape on soft materials (Engler et al., 2004).

Polyurethanes (PUs) are a very diverse family of polymers capable of exhibiting a wide range of properties, depending on their molecular composition and preparation conditions. They can be smooth elastomeric membranes or rigid matrices in the form of sponges, fibres, films or tubes and have therefore found various applications in medical areas (Hasirci, 1991; Burke and Hasirci, 2004). PUs are known as haemocompatible materials, but still an intense research is going on to improve their haemocompatibility and biocompatibility by changing the chemical composition or by modifying them using various techniques or with bioactive molecules (Kutay et al., 1990; Kayirhan et al., 2001; Ozdemir et al., 2002; Aksoy et al., 2008; Nelson et al., 2012). In PUs, there are flexible 'soft segments', which are generally long chains of polyols, and rigid 'hard segments', which are the result of the reactions between isocyanates and chain extenders. These domains create microphase separation and alter the mechanical, thermal and other properties of the resultant polymer (Ulubayram and Hasirci, 1992; Hasirci and Aksoy, 2007). Biodegradable PUs can be synthesized by using ester-containing groups to enhance enzymatic and hydrolytic disintegration. For this purpose, various diols, such as poly(caprolactone) diol (PCL diol), can be reacted with diisocyanate-containing amino acid molecules (Marcos-Fernández et al., 2006; Kiziltay et al., 2012). Polycaprolactone (PCL) has been widely studied and used in the production of medical devices. It has a special place in the production of bone tissue-engineering scaffolds because of its biocompatibility, ease of processing and the ability to manipulate mechanical and degradation properties, either as homopolymers or copolymers (Diba et al., 2011; Sharaf et al., 2012). Especially, its low melting temperature and good thermal stability enable PCL scaffolds to be designed and fabricated using rapid prototyping techniques without applying high-temperature conditions.

In the present study, a lysine based poly(ester-urethane) (PEU) was synthesized from PCL diol and lysine diisocyanate (LDI) and, by using this polymer, scaffolds with different physical forms were prepared with different designs, porosity and flexibility, using conventional salt-leaching and advanced rapid prototyping techniques. The influence of design, porosity and matrix stiffness on the properties and osteoblastic activity was examined using rat bone marrow stem cells.

\section{Experimental}

\subsection{Materials}

Lysine-based PEU was synthesized from PCL diol (MW = 1250; Sigma-Aldrich, Germany) and lysine diisocyanate (LDI; diisocyanate of the L-lysine methyl ester, kindly donated by Kyowa Hakko Kogyo Co. Ltd, Japan) by using stannous octoate (Sigma-Aldrich) as catalyst. The method for the synthesis of PEU was described previously (Kiziltay et al. 2012). The other chemicals were obtained from the following suppliers: 1,4-dioxane from Scharlau (Spain); dexamethasone, $\beta$-glycerophosphate disodium salt and L-ascorbic acid from Sigma-Aldrich; bovine serum albumin (BSA) from Fluka (USA); Dulbecco's modified Eagle's medium (DMEM, high-glucose) and fetal bovine serum (FBS) from Hyclone (USA); penicillin-streptomycin (Pen-Strep) solution from HQClone; trypsin-EDTA (0.25\%), glutaraldehyde, cacodylic acid (sodium salt) and lipase from Pseudomonas fluorescens (40 U/mg) from Sigma (USA); fibrinogen from Roche (Germany); AlexaFluor 488 phalloidin and DAPI from Chemicon (USA); nucleocounter reagents from Chemometec (Denmark); and Alamar blue cell proliferation assay from Biosource (USA).

\subsection{Scaffold fabrication}

\subsubsection{Scaffold fabrication using rapid prototyping technique}

PEU scaffolds were fabricated layer by layer, using a rapid prototyping technique (Bioplotter $\AA$, Envisiontec $\mathrm{GmbH}$, Germany). Briefly, bulk polymer was placed in a stainless steel syringe (needle length $28.1 \mathrm{~mm}$, needle inner diameter $0.5 \mathrm{~mm}$ ) and heated to $105^{\circ} \mathrm{C}$. When the polymer melted, $\mathrm{CO}_{2}$ pressure $(5 \mathrm{mmHg})$ was applied to the syringe through a pressurized cap. Rectangular block models $(20 \times 20 \mathrm{~mm})$ were uploaded on the Bioplotter and the 3D scaffold was plotted up to eight layers through the extrusion of the polymer as fibres. Each layer had a thickness of about $0.4 \mathrm{~mm}$, yielding a final eight-layered scaffold with a thickness of $\sim 3 \mathrm{~mm}$. Scaffolds with two different architectures were produced by changing the respective orientation of the deposited fibres, using CAD/CAM software. The basic architecture (BP-B) was produced by consecutive deposition of the layers, where each layer $(\mathrm{N})$ was plotted orthogonally to the layer below (N-1) and was plotted in the same relative position as layer N-2 (Figure 1b). The offset architecture (BP-O) was similar to BP-B, but layer $\mathrm{N}$ is plotted with in an offset distance relative to layer N-2 (Figure 1c). Finally the scaffolds were cut using a circular punch, $6 \mathrm{~mm}$ in diameter, and used for further experiments.

\subsubsection{Fabrication of scaffolds by salt-leaching}

PEU solution ( $15 \% \mathrm{w} / \mathrm{v}$ in dioxane) was poured into glass Petri dishes, frozen at $-20^{\circ} \mathrm{C}$ and lyophilized in a freeze- 

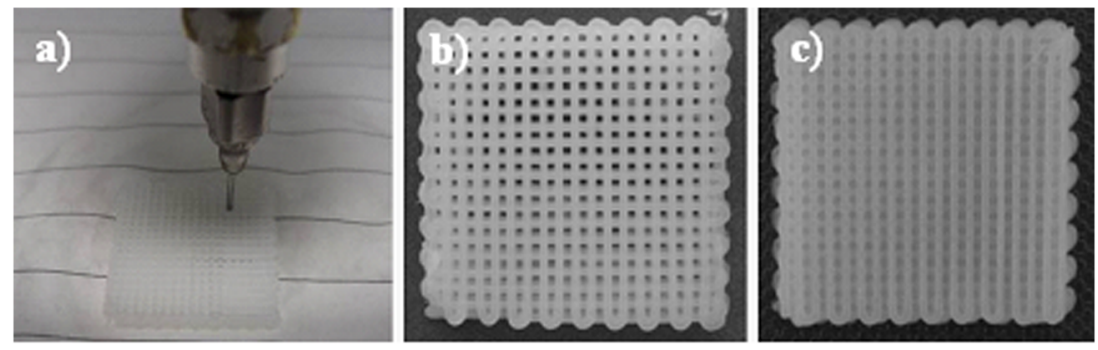

Figure 1. Plotting of melted PEU: (a) layer-by-layer; (b) BP-B; (c) BP-O $(20 \times 20 \times 3 \mathrm{~mm})$

dryer (Labconco Freeze Dry, Model 78680, MO, USA). In order to obtain a highly porous matrix, sieved salt crystals $(180-300 \mu \mathrm{m})$ were added into the PEU solution in dioxane (polymer:salt ratio $1: 5$ or $1: 10 \mathrm{w} / \mathrm{w}$ ). The solution-salt mixture was poured into glass Petri dishes and processed as described above. After drying, the samples were cut with a puncher (diameter $6 \mathrm{~mm}$ ) and the salt-containing samples were immersed in distilled water for 2 days and washed by changing the liquid several times to remove all salt particles. Prepared saltleached sponges were designated SP5 and SP10 for the samples with polymer:salt ratios of $1: 5$ and $1: 10$, respectively.

\subsection{Thermal characterization}

The thermal behaviours of scaffolds were characterized by differential scanning calorimetry (DSC) and thermogravimetric analysis (TGA). DSC was used to determine the glass-transition temperature $\left(T_{\mathrm{g}}\right)$ and crystalline melting temperatures $\left(T_{\mathrm{m}}\right)$ under a nitrogen atmosphere, using a DuPont 2000 Differential Scanning Calorimeter at a rate of $10^{\circ} \mathrm{C} / \mathrm{min}$ in the temperature range $-100^{\circ} \mathrm{C}$ to $100^{\circ} \mathrm{C}$. Thermal stability and thermal decomposition investigations of the polymer were achieved by thermogravimetric analysis, using a Perkin-Elmer Pyris 1 TGA instrument (USA) under a nitrogen atmosphere.

\subsection{Determination of porosity and pore size distribution}

Scaffold porosity was determined using a liquid displacement method with a pycnometer. The sample and the empty pycnometer with glass stopper was weighed and recorded as $m_{\mathrm{s}}$ and $m_{\mathrm{p}}$, respectively. The weight of the pycnometer filled with decane (non-solvent for the samples) was recorded as $m_{1}$. The total weight containing the sample (pycnometer + decane + sample) was recorded as $m_{2}$. Mass of decane $\left(m_{\mathrm{d}}\right)$ was found by subtracting $\left(m_{\mathrm{s}}+m_{\mathrm{p}}\right)$ from $m_{2}$. Volume of pycnometer $\left(V_{1}\right)$ was calculated as follows: $V_{\mathrm{l}}=\left(m_{1}-m_{\mathrm{p}}\right) / \rho_{\mathrm{d}}$, where $\rho_{\mathrm{d}}$ is the density of decane.

Volume of the sample $\left(V_{\mathrm{s}}\right)$ was calculated by taking the volume differences of decane and the pycnometer. The percentage porosity $(P)$ of each scaffold was determined according to the following equation: $P(\%)=\left[\left(V_{\mathrm{a}}-V_{\mathrm{s}}\right) / V_{\mathrm{a}}\right] \times 100$, where $V_{\mathrm{a}}$ is the apparent volume of the cylindrical sample calculated from its dimensions.

Pore size distributions of the freeze-dried and saltleached scaffolds were determined using a Mercury intrusion porosimeter (Quartachrome Corp., USA).

The porosity of the bioplotted scaffolds were assessed by micro-computed tomography ( $\mu \mathrm{CT}$; m-CT 20, Scanco Medicals, Switzerland). Scanner settings were $40 \mathrm{keV}$ and $248 \mathrm{~mA}$. Entire scaffolds were scanned in around 200 slices.

\subsection{Mechanical tests}

The compressive mechanical properties of PEU scaffolds were studied using a Lloyd LRX $5 \mathrm{~K}$ Mechanical Tester, controlled by a computer running program (WindapR). For compression tests, samples in cylindrical shape were placed between compression presses and compressed at a speed of $2 \mathrm{~mm} / \mathrm{min}$. The compressive elastic modulus was evaluated from the initial linear elastic region of the stress-strain curves.

\subsection{In situ degradation profiles of scaffolds}

The stability of the various types of scaffolds was evaluated by incubating in aqueous media, with and without the presence of Pseudomonas lipase enzyme. Degradation experiments were carried out according to the Standard ASTM F-1635. For enzymatic degradation, each scaffold was placed into a vial containing $5 \mathrm{ml}$ PBS (0.1 M, pH 7.4) with $0.18 \mathrm{U} / \mathrm{ml}$ enzyme and $0.02 \%$ sodium azide to inhibit bacterial growth, and incubated at $37^{\circ} \mathrm{C}$ in a water bath shaker. The solutions were changed every day. Samples were removed periodically, washed with distilled water, freeze-dried and weighed in order to determine the weight loss due to degradation. The weighed samples were then placed back into fresh PBS medium containing enzyme. The same steps were followed for hydrolytic degradation, except that enzyme was not added into the PBS solution. Three parallel experiments were carried out for each type of specimen and the measured values were averaged. Percentage of weight loss was calculated as follows: weight loss $(\%)=\left[\left(W_{0}-W_{1}\right) / W_{0}\right] \times 100$, where $W_{0}$ and $W_{1}$ are the weight of the dry sample before and after hydrolytic or enzymatic degradation, respectively. 


\subsection{In vitro studies}

\subsubsection{Modification of PEU scaffolds with oxygen plasma}

All 3D scaffolds were treated with oxygen plasma in order to enhance the wettability of the samples prior to cell culture tests. For this purpose, 3D scaffolds were placed in a plasma chamber (with a SEREN IPS R $30013.56 \mathrm{MHz}$ power supply; Advanced Plasma Systems, St. Petersburg, USA) and subjected to oxygen plasma $(100 \mathrm{~W})$ for $3 \mathrm{~min}$. The samples were then sterilized under UV light for $30 \mathrm{~min}$ for each surface and then used in cell culture studies.

\subsubsection{Isolation and culture of mesenchymal osteoprogenitor cells}

Bone marrow stem cells (BMSCs) were obtained from the femoras and tibias of 6 week-old, male Sprague-Dawley rats and cultured as previously described (Yilgor et al., 2008). All procedures were in full compliance with Turkish Law 6343/2 (Veterinary Medicine Deontology Regulation 6.7.26) and with the Helsinki Declaration of Animal Rights (Bennett, 1994). $100 \mu$ l cell suspension containing $5 \times 10^{4}$ cells were seeded on each sample and incubated for $30 \mathrm{~min}$ at $37^{\circ} \mathrm{C}$ to allow cell attachment. Then $1 \mathrm{ml}$ osteogenic medium (DMEM supplemented with 10\% FCS, $10 \mathrm{~mm} \beta$-glycerophosphate, $50 \mu \mathrm{g} / \mathrm{ml} \mathrm{L}$-ascorbic acid and $10 \mathrm{~nm}$ dexamethasone in the presence of $100 \mathrm{U} / \mathrm{ml}$ penicillin and $100 \mu \mathrm{g} / \mathrm{ml}$ streptomycin) was added. The cells on the scaffolds were then allowed to grow for predetermined periods at $37^{\circ} \mathrm{C}$ in a humidified atmosphere containing $5 \% \mathrm{CO}_{2}$ and the medium was changed every other day.

\subsubsection{Microscopy and image analysis}

The microstructures of 3D PEU scaffolds were characterized using scanning electron microscopy (SEM; FEI Quanta $400 \mathrm{~F}$, Holland). The samples were mounted on aluminium stubs and sputter-coated with gold-palladium (AuPd) under an argon atmosphere. For examination of cell morphology and deposited minerals, cell-seeded samples were fixed with $2.5 \%$ glutaraldehyde in $0.14 \mathrm{M}$ sodium cacodylate buffer, $\mathrm{pH} 7.4$, for $2 \mathrm{~h}$ at room temperature, rinsed in cacodylate buffer and freeze-dried. The mean pore sizes of all scaffolds were determined using ImageJ software.

\subsubsection{Cell proliferation}

The numbers of viable cells in the samples were assessed using Alamar blue assay (US Biological) at different time points. Prior to the measurements, the culture medium in the wells was discarded and the wells washed with sterile PBS to remove any remaining medium. Alamar blue solution (10\%, $1 \mathrm{ml}$ in colourless DMEM) was added to the wells and incubated at $37^{\circ} \mathrm{C}$ and $5 \% \mathrm{CO}_{2}$ for $1 \mathrm{~h}$. Then, $200 \mu$ l test solution was transferred to a 96 -well plate and absorbance values were determined at $570 \mathrm{~nm}$ and $595 \mathrm{~nm}$, using a plate reader (V max Microplate Reader, Molecular Devices, USA). The test medium in the wells was then discarded, washed with sterile PBS, fresh complete medium was added to the wells and the incubation was continued.

\subsubsection{Determination of matrix mineralization}

Mineralization on 3D scaffolds was examined by von Kossa staining and SEM/EDX analysis after 5 weeks of culture. For von Kossa staining, seeded scaffolds were fixed with 4\% paraformaldehyde for $15 \mathrm{~min}$, washed with distilled water and incubated in $5 \% \mathrm{AgNO}_{3}$ under UV light for $30 \mathrm{~min}$. After rinsing with distilled water many times, the samples were treated with 5\% sodium thiosulphate for $5 \mathrm{~min}$ in order to remove unreacted silver. Then the samples were rinsed in distilled water several times before visualization under light microscopy. For EDX analysis, samples were prepared in the same way as described for SEM analysis.

\section{Results and discussion}

\subsection{Thermal properties}

The response of a polymer to heat is important, since it causes variations in the physical properties of the material at different temperatures. The glass transition temperature $\left(T_{\mathrm{g}}\right)$ of PEU synthesized in this study is below room temperature, and PEU shows elastomeric behaviour at body temperature. The thermal properties of the prepared PEU matrices were determined by DSC and TGA. The first-heating DSC thermograms and TGA curves for different specimens, namely unprocessed polymer in the smooth film (SF) form, freeze-dried sponge (SP0), saltleached sponge (SP10) and bioplotted basic (BP-B) structured samples, are presented in Figure $2 \mathrm{a}$ and $\mathrm{b}$, respectively. All samples demontrated similar $T_{g}$ values (in the range $-45^{\circ} \mathrm{C}$ to $-43^{\circ} \mathrm{C}$ ), while the melting peaks $\left(T_{\mathrm{m}}\right)$ showed some shifts (about $45^{\circ} \mathrm{C}, 41^{\circ} \mathrm{C}, 40^{\circ} \mathrm{C}$ and $51^{\circ} \mathrm{C}$ for SF, SP0, SP10 and BP-B, respectively), as can be observed in Figure 2. Except for SP0, the other samples had multipeaks demonstrating the existence of crystals of different sizes and/or imperfections. High Tm values were obtained for bioplotted ones; this was expected, since these samples get some chain orientation during processing. For BP-B, the peak near $39^{\circ} \mathrm{C}$ is probably due to melting of small and imperfect crystallites formed during processing of macro-chains, whereas the peak with the highest melting point of all the studied samples, at $51^{\circ}$ $\mathrm{C}$, is due to a more perfect orientation of chains forming the crystal domains.

The low melting point is desirable for melt-processing techniques; however, $T_{\mathrm{m}}$ at around $45^{\circ} \mathrm{C}$ makes the polymer unsuitable for thermal sterilization. Thus, the differences in melting thermograms can be attributed to 

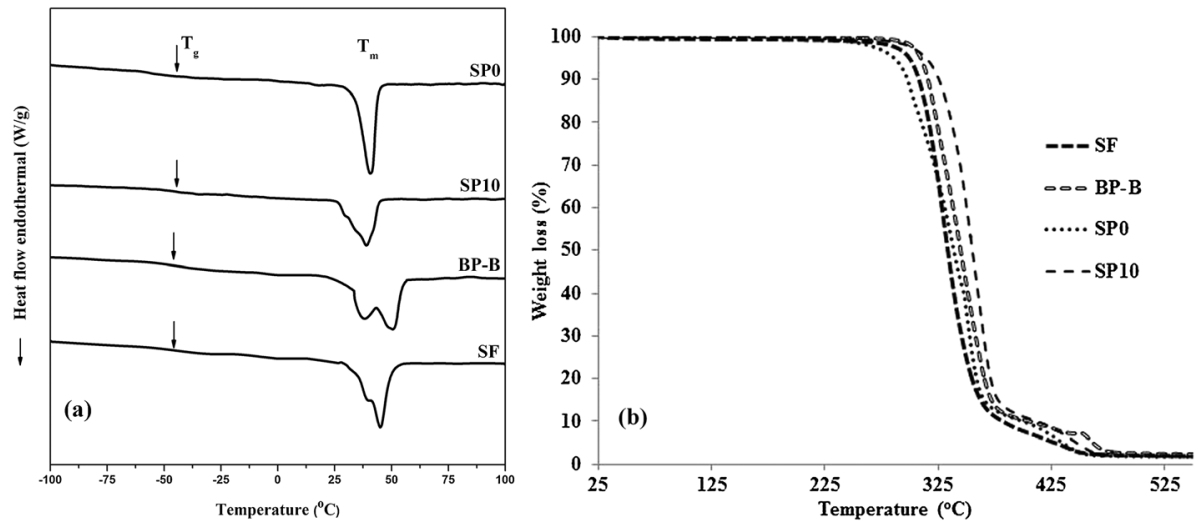

Figure 2. (a) DSC thermograms of PEU matrices and (b) TGA curves of smooth film (SF), freeze-dried (SP0), salt-leached (SP10) and bioplotted (BP-B) samples

different preparation of the mentioned three specimens: The cast films, freeze-dried and salt-leached samples were prepared in dioxane; bioplotted samples were obtained by a melting process. Therefore, solvent effect and melting process affected the orientation of the chains, the intermolecular forces between them and the crystallization with different thermal responses.

TGA thermographs showed the thermal stability of the polymer up to $250^{\circ} \mathrm{C}$, and above that temperature a similar weight loss pattern was observed for all samples, solvent-cast films, freeze-dried sponges, salt-leached sponges or rapid prototyped structures (Figure $2 \mathrm{~b}$ ). The degradation temperatures were detected around $250^{\circ} \mathrm{C}$, $270^{\circ} \mathrm{C}, 280^{\circ} \mathrm{C}$ and $290^{\circ} \mathrm{C}$ for SP0, SP 10 , SF and BP-B, respectively. The lowest degradation temperature was observed for freeze-dried sponges and shifted to higher values. This can be explained as follows: the presence of charged salt particles can cause some ionic interactions with the polar sides of the macro-chains. This interaction leads to organization of the macro-chains. Similar organizations and stronger interactions between polymeric chains could also occur in films and bioplotted scaffolds. These interactions enhance thermal stability and shift the degradation temperature to higher values (Figure 2b).

\subsection{Morphology of unseeded scaffolds}

The morphology and pore interconnections of porous structures of the 3D scaffolds were examined by SEM (Figure 3). The bioplotted scaffolds as basic (BP-B) or as offset (BP-O) configurations had fully interconnected pore architectures with a strand diameter, strand distance and pore size of $\sim 450 \mu \mathrm{m}$. SEM images of all scaffolds were analysed via the ImageJ program to obtain average pore size values. According to this image analysis, the scaffolds were found to have an average pore size of $80 \mathrm{~m}, 207$,
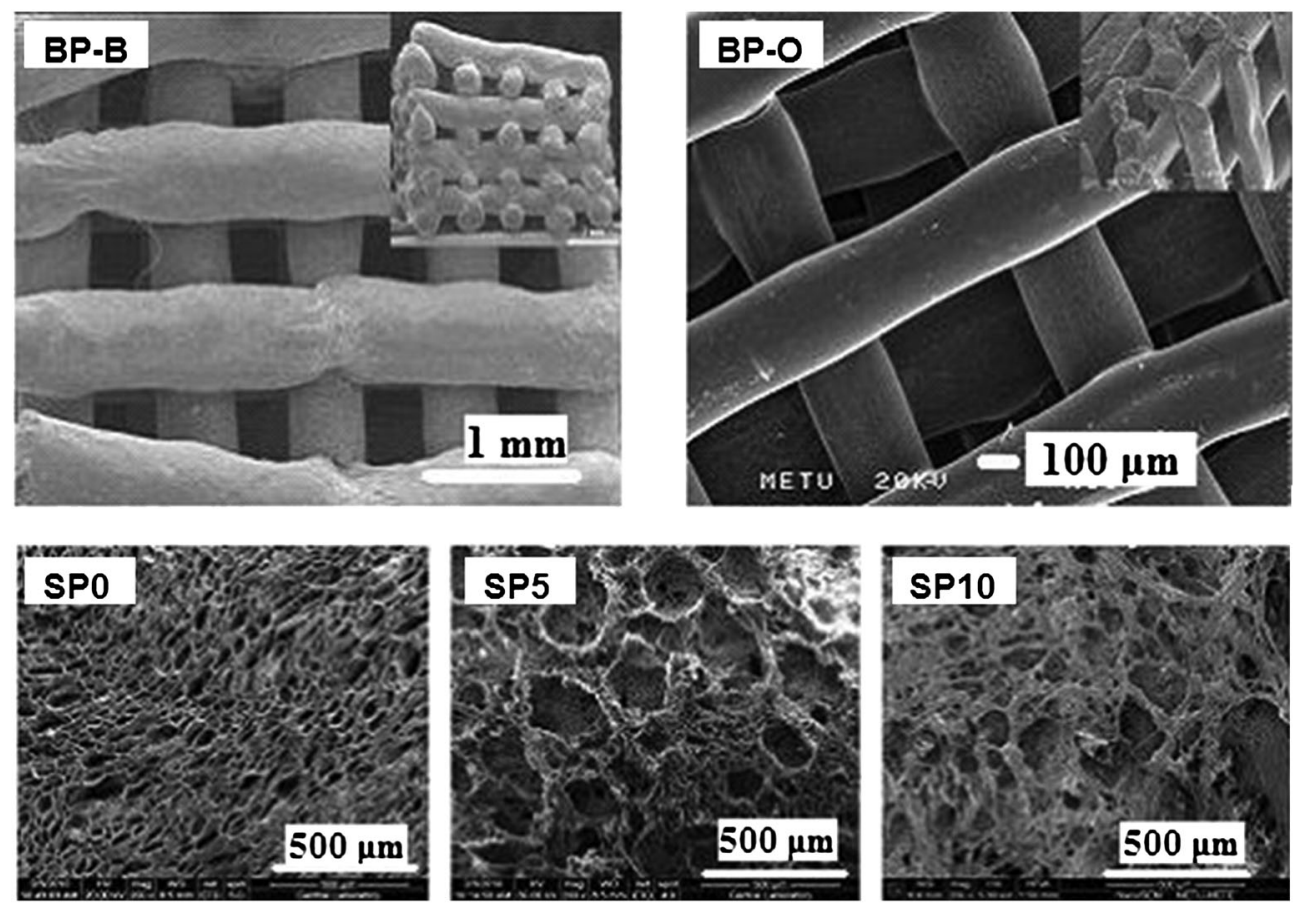

Figure 3. SEM images of PEU scaffolds fabricated by Bioplotter (BP-B and BP-O), freeze-drying (SP0) and salt-leaching (SP5 and SP10) 
Table 1. Porosity and compressive modulus values of the 3D scaffolds

\begin{tabular}{lccccc}
\hline Sample* & Weight $(\mathrm{mg})$ & Mean pore size $(\mu \mathrm{m})$ & Pore size range $(\mu \mathrm{m})$ & Porosity $(\%)$ & Compressive modulus $(E, \mathrm{kPa})$ \\
\hline SP0 & $28 \pm 3$ & 80 & $20-120$ & 33 & $584 \pm 66$ \\
SP5 & $19 \pm 4$ & 207 & $30-300$ & 85 & $146 \pm 6$ \\
SP10 & $12 \pm 4$ & 230 & $30-350$ & 96 & $38 \pm 2$ \\
BP-B & $36 \pm 2$ & 421 & $350-500$ & 65 & $4720 \pm 540$ \\
BP-O & $36 \pm 2$ & 488 & $350-500$ & 56 & $3450 \pm 610$ \\
\hline
\end{tabular}

*Sample dimensions: $d=6 \mathrm{~mm}, \mathrm{~h}=3 \mathrm{~mm}$.

230, 421 and $488 \mu \mathrm{m}$ for SP0, SP5, SP10, BP-B and BP-O, respectively, with the pore diameters in the ranges 20-120, 30-300, 30-350, 350-500 and 350-500 $\mu \mathrm{m}$, respectively (Table 1$)$.

The surface area:volume ratios of the salt-leached (SP5 and SP10) sponges were greatly increased compared to SP0 sponges obtained by freeze-drying. A higher surface area:volume ratio provides more space for the cells to attach, and thus would increase the percentage of total cells interacting and proliferating in the scaffolds. SEM images also revealed the presence of numerous pore interconnections, with at least $30 \mu \mathrm{m}$ pores in salt-leached scaffolds, which were expected to promote vascular and tissue ingrowth when implanted.

\subsection{Porosities, pore size distributions and mechanical properties of scaffolds}

The microstructures of the scaffolds are defined by their pore size and porosity values. Porosity refers to the overall percentage of void space within a solid, whereas pore size indicates the diameter of individual voids in the scaffold (Kim et al., 2010). It is of general acceptance that porosity, mean size, pore size distribution and pore interconnectivity play a critical role in scaffold design and production because of their importance for cell migration, proliferation and ECM formation (Hong et al., 2008). Permeability of a scaffold is also important for nutrition diffusion and waste clearance. Some researchers reported the pore size as determinant for sufficient tissue ingrowth, where a minimum pore size for tissue ingrowth and vascularization was indicated as $100 \mu \mathrm{m}$ (ASTM F2450), while some others suggested that the controlling factor is the pore interconnection size, which is related to both pore size and the extent of porosity. A minimum pore diameter is important so that as the cells proliferate, the pore diameter will eventually drop and might inhibit the penetration of the cells and lead to a decrease in cell viability. For bone tissue engineering, the ability of a scaffold to enhance osteogenic differentiation and support new bone formation is dependent pretty much on the pore size, porosity and pore interconnectivity of the scaffold. The importance of scaffold porosity and pore size can be attributed to the native structure of bone, which itself is a porous tissue. Cortical bone is mainly a dense structure, but its small porous region (10\% of the total) allows vascularization and cellular infiltration. In contrast, cancellous bone has a highly porous structure (50-90\%) (Mistry and Mikos, 2005). In this study, the percentage porosity values of the bioplotted scaffolds were found to be $65 \%$ and $56 \%$ for BP-B and BP-O, respectively. As observed from the SEM images, the pores were interconnected throughout the whole structure, with a controlled pore size of ca. $450 \mu \mathrm{m}$. This is especially important, as most scaffolds produced by conventional methods do not have interconnectivity and the pore sizes may have variations in the structure. The percentage porosity of the freeze-dried scaffolds was found to be $33 \%$ using the pycnometer. Leaching by salt particles caused an increase in the porosity of up to $85 \%$ and $96 \%$, depending on the amount of salt particles used. The porosity profiles of all 3D scaffolds are shown in Table 1.

Pore size distribution analysis was not applied for bioplotted scaffolds, since they were produced with homogeneous pore sizes. For the samples prepared by freeze-drying and salt-leaching, pore size distribution plots confirmed SEM observations. The results showed that pores with sizes of $5 \mu \mathrm{m}$ are present in all scaffolds, even those prepared with a high salt content. Figure 4a shows distributions of
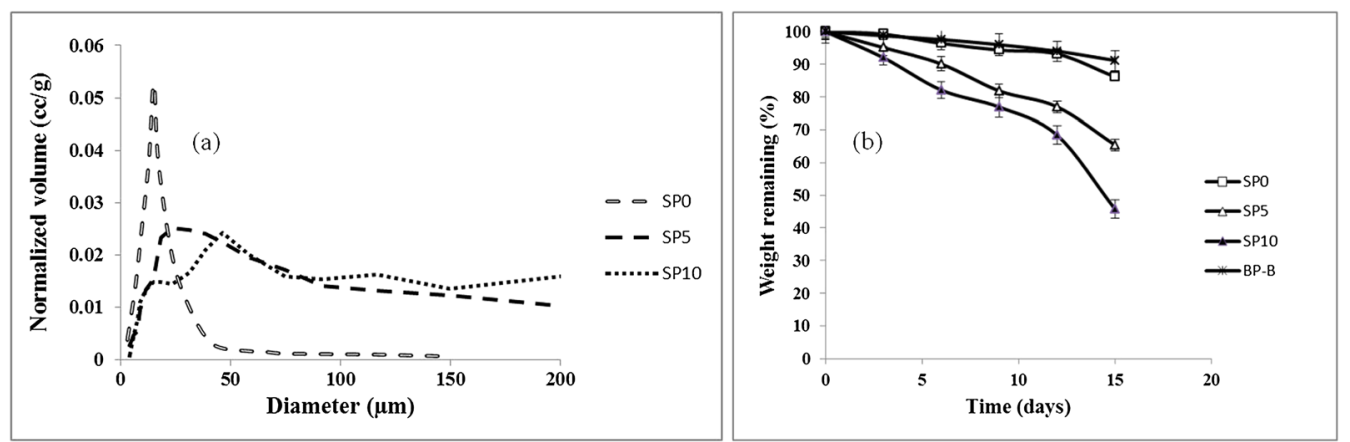

Figure 4. (a) Pore size distributions of spongy scaffolds prepared by freeze drying (SP0) and salt-leaching (SP5 and SP10); and (b) degradation profiles of 3D scaffolds in PBS with $0.18 \mathrm{U} / \mathrm{ml}$ lipase $(n=3)$ 
pore sizes of spongy scaffolds in the range $5-200 \mu \mathrm{m}$, as obtained from a mercury porosimeter. It is seen that the overall macroporosities of SP5 and SP10 were higher than that of SP0, as expected. In SP5 and SP10, the fraction of bigger pores increased with the addition of salt particles. For SP0, the fraction of pores $>50 \mu \mathrm{m}$ is negligible, while for SP5 and SP10 there is a considerable fraction $>200 \mu \mathrm{m}$.

Scaffold features such as pore structure, mechanical strength and degradation properties play important roles in the growth and function of cells, since specific cells need mechanical stimuli generated by the scaffold to mediate cell stiffening, due to cell focal adhesion attachments (Hing, 2005). Thus, parameters such as molecular weight, crystallinity, microstructure (porosity, mean pore size, pore shape, interconnectivity, specific surface area, etc.) and preparation method that influence scaffold stiffness would inherently influence the cell response. Different cells show varying responses. For example, mesenchymal stem cells (MSCs), fibroblasts and epithelial cells have been shown to exhibit better cell spreading, adhesion and proliferation on stiffer scaffolds (Keogh et al., 2010).

Compressive elastic modulus is a measure of material stiffness. In this study, spongy scaffolds (SP0, SP5 and SP10) exhibited similar stress-strain behaviour characteristic of low-density, elastomeric open-cell foams as defined by Harley et al. (2007). As seen in Table 1, bioplotted scaffolds (BP-B and BP-O) displayed significantly higher compressive stiffness than the spongy scaffolds obtained by freeze-dried (SPO) and salt-leached (SP5 and SP10) samples. Addition of leaching particles decreased the compressive elastic modulus of SP0 from $584 \pm 66 \mathrm{kPa}$ to $146 \pm 6 \mathrm{kPa}$ for SP5 and to $38 \pm 2 \mathrm{kPa}$ for SP10 under dry conditions, as expected. In the case of bioplotted scaffolds, it was observed that alteration of fibre orientation from basic (BP-B) to offset (BP-O) architecture led a decrease in compressive modulus from $4720 \pm 540 \mathrm{kPa}$ to $3450 \pm 610 \mathrm{kPa}$, due to juxtaposition of sequential fibres along the $z$ axis. Yilgor et al. (2008, 2010) also showed that scaffolds with basic configuration exhibited higher mechanical strength. Mechanical properties can be attributed to differences in micro-architecture and porosity. SP10 had the highest porosity, with a value of $96 \%$, and thus showed the lowest mechanical strength, while bioplotted BP-B and BP-O had the highest elastic modulus values. This can be explained by reorientation of PEU chains during melt processing to form strong molecular interactions and a more crystalline structure, as confirmed by DSC and degradation studies. Increase of crystalline amount leads to increase in mechanical strength.

As a supportive matrix for cell culture, a scaffold must have appropriate mechanical strength. Generally, the optimum value for mechanical strength is correlated with the strength of the target tissue, but a strength of at least $100 \mathrm{kPa}$ is reported to be necessary (Zhang et al., 2006). Compressive moduli for cancellous bone are given as 50-500 MPa, depending on anatomical location (Hench, 1991). When compared to natural bone, it is seen that the compressive moduli of all prepared scaffolds, including bioplotted ones, were lower than this reported range. On the other hand, prepared scaffolds seem to have potential mechanical stiffness to support osteogenic differentiation. It has been indicated that scaffold stiffness plays an important role to induce differentiation into the osteogenic lineage. It was shown that human MSCs differentiated into osteogenic phenotypes on two-dimensional (2D) substrates with elastic modulus $>34 \mathrm{kPa}$; below this value, MSCs differentiated into neural or myogenic phenotypes (Pek et al., 2010). They further confirmed the effect of matrix stiffness on the differentiation of human MSCs in 3D scaffolds. These findings showed that PEU-based scaffolds are not useful for load-bearing applications, but can be used for bone defects which demand only low compressive strength and for soft tissue applications.

\subsection{In situ degradation profiles of PU scaffolds}

PEU matrices obtained by freeze-drying, salt-leaching and bioplotting were incubated in PBS in either the presence or absence of lipase. Lipase is an enzyme present in human serum, responsible for hydrolysis of ester bonds in polyesters (Calil et al., 2007). In this study, PEU matrices immersed in PBS with no enzyme addition did not show any significant weight loss up to 30 days (data not shown). On the other hand, under enzymatic conditions, different forms of PEU matrices had different weight loss profiles, as shown in Figure 4b.

The order of the remaining weights after 15 days of enzymatic incubation was found to be: SP10 (46\%) < SP5 $(65 \%)<$ SP0 $(86 \%)<$ BP-B (91\%). Salt-leached scaffolds with high salt concentrations (SP10) presented the greatest weight loss among the five specimens when immersed in lipase-containing solution. This can be explained by the presence of larger pore sizes, higher interconnectivity and higher surface area due to higher porosity, and therefore higher exposure to enzyme solution. Controlling the degradation rates of synthetic polymer scaffolds is one of their advantages over natural materials. Scaffolds produced from synthetic polymers such as PCL could preserve their structure without showing any degradation when incubated in PBS for years, due to their hydrophobicity (Gan et al., 1999), but it is also possible to control the biodegradation by changing the composition and by adding ingredients into the composition.

\subsection{In vitro studies}

\subsubsection{Surface modification of $3 D$ scaffolds}

The surface topography and hydrophobicity of scaffolds play critical roles in regulating initial cell behaviours, such as cell adhesion and proliferation. Oxygen plasma treatment is widely used for surface modification of cell carrier materials to make the surface hydrophilic and to enhance cell adhesion and proliferation (Hasirci 
A. Kiziltay et al.
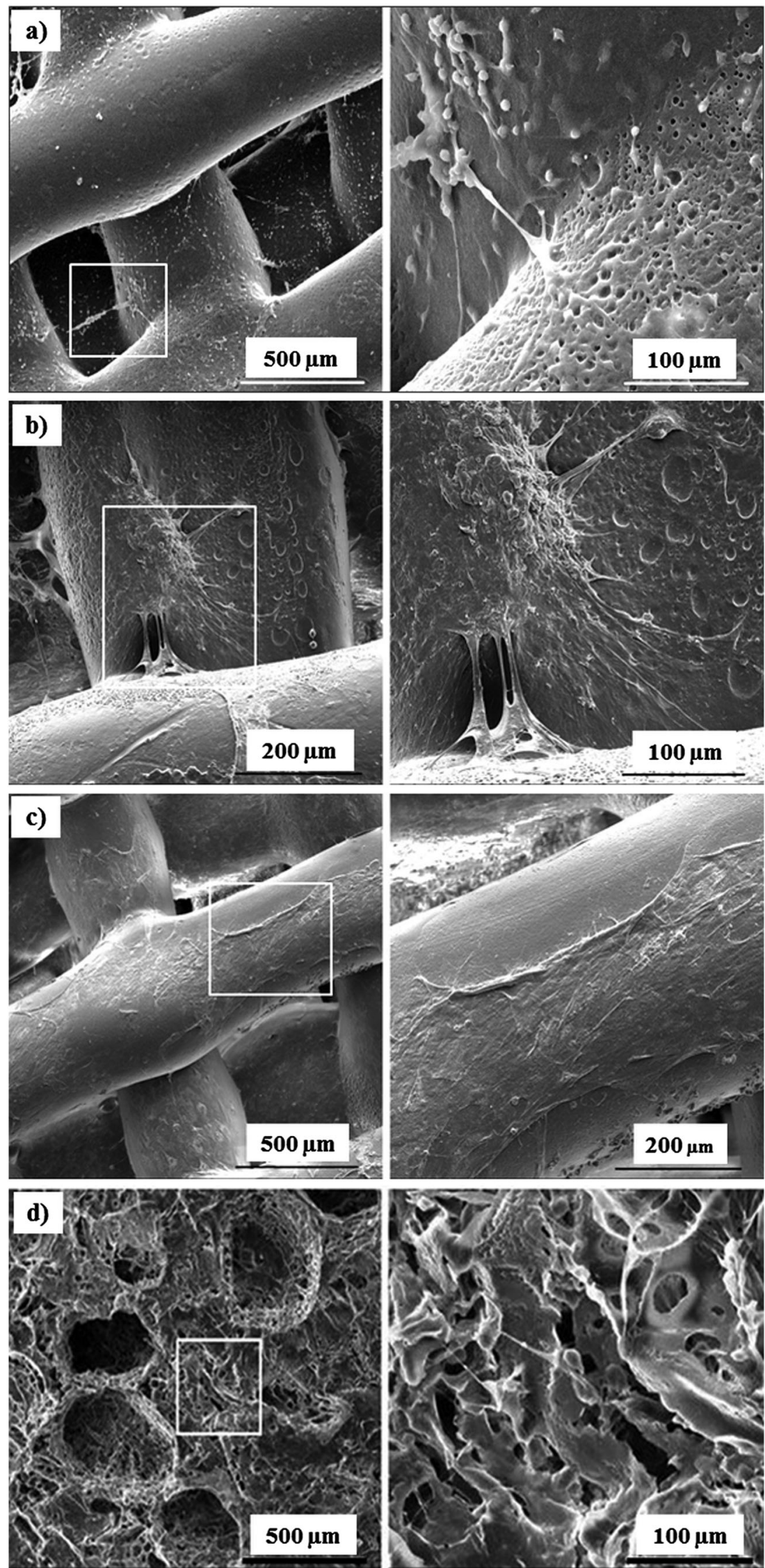

Figure 5. SEM images showing the interaction between the cells and scaffolds of BP-O (a-c) and SP10 (d) representing salt-leached and bioplotted samples, respectively. Images in the right column are higher magnifications of the corresponding areas indicated on the left 
et al., 2003). In this part of the study, 3D scaffolds were treated with oxygen plasma in order to increase wettability by decreasing the surface contact angle. After plasma treatment, cell suspension droplets were immediately absorbed by the scaffolds, while they continued to stay as droplets on the surfaces of untreated samples.

\subsubsection{Morphology of seeded scaffolds}

BMSCs showed good adherent ability on both bioplotted and salt-leached scaffolds, on which a layer of cells can be detected (Figure 5). Cells were attached closely with neighbouring cells and formed a cellular network on struts as well as within the pores of salt-leached scaffolds. Cell layers as well as bridging on bioplotted fibres were observed. The morphology of the seeded scaffolds indicates good interaction of scaffolds with the cells. SP0 samples were not used for in vitro culture, due to their relatively small pore size and low porosity.

\subsubsection{Cell proliferation on $3 D$ scaffolds}

Proliferation ability of BMSCs on scaffolds is shown in Figure 6. It is known that 3D scaffolds play a vital role in providing the base for growing cells to adhere and proliferate. In order provide adequate space for cell adhesion, migration, growth and vascular supply, scaffolds should have micrometer range pores, high porosity and interconnectivity, which will also maintain proper fluid circulation in the scaffold (Mandal et al., 2009). For this purpose, an optimum pore size is needed (pores larger than the size of cells, preferably $>100-150 \mu \mathrm{m}$ ) (Hollis and Flahiff, 1995), as well as adequate size of interconnections to facilitate cell bioactivities. This is especially important in bone tissue engineering, where vascularization is limited (Mitsak et al., 2011). Many studies have pointed to the importance of permeability for the proliferation of cells. Mandal et al. (2013) reported better cell proliferation in scaffolds with a smaller pore size $(80-100 \mu \mathrm{m})$ but with higher porosity (96\%), compared to those with higher pore size $(200-250 \mu \mathrm{m})$ but lower porosity (86\%). Freeze-drying and the use of porogen agents is one of most utilized method to obtain macroporous materials. However, uncontrolled size and shape of macropores and interconnections between them, as well as low mechanical properties, are the main concerns. Similarly, electrospinning is a preferred method for producing scaffolds, but low interconnectivity and pore sizes in the nanommeter range are the primary factors limiting the extensive use of electrospun scaffolds in tissue engineering. Joshi et al. (2013) applied a laser cut method to electrospun scaffolds in order to obtain larger pore sizes $(300 \mu \mathrm{m})$ and porosity. They indicated that the distances of cellular infiltration were about $350 \mu \mathrm{m}$ and $1000 \mu \mathrm{m}$ across all layers when rolled scaffolds without and with laser cut, respectively, were used. Mitsak et al. (2011) reported that enhanced bone penetration and vascularization was observed in vivo when scaffold permeability was greater. By micro-CT evaluation, they showed bone penetration into high permeability scaffolds, with blood vessel infiltration after 4 weeks.

In our studies, it was observed that the number of cells attached on SP5 and SP10 was almost the same, while it was relatively lower on bioplotted scaffolds (BP-B and BP-O) on the first day. This was expected, due to the flow of cell suspension through the very big pores (about $400 \mu \mathrm{m}$ ) of these samples. The number of initially attached cells was significantly higher on BP-O scaffolds than that on BP-B scaffolds, due to a higher available surface area in the flow path of the cell suspension. If there is no fibre positioned as offset, there is a direct open path for cells to escape from the scaffolds. On the other hand, fibres in an offset position act as a barrier to prevent cell flow, which further leads to a higher amount of initial adhesion and proliferation. One point that should be emphasized is the deformation in the bioplotted scaffold fibres. The thickness and distances between the fibres of

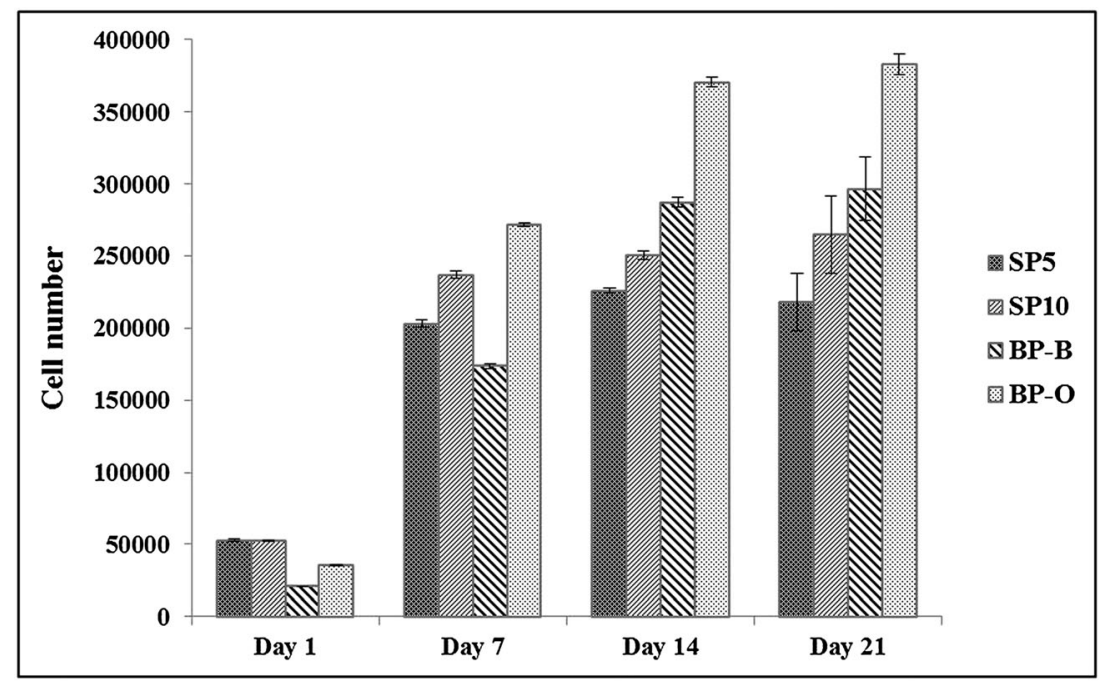

Figure 6. Proliferation of BMSCs on 3D scaffolds $(n=3)$ 
bioplotted scaffolds are in the range 400-500 $\mu \mathrm{m}$. In some parts, because of the difficulty of flow of the polymeric material through the syringe, some variations in the thickness (about $-70 \mu \mathrm{m}$ ) occurred. The minimum thickness in the narrowing area was measured as $380 \mu \mathrm{m}$. If the cell size (around $10-30 \mu \mathrm{m}$ ) is taken in account, the variation in fibre thickness is too high for cells to recognize. Therefore, no significant effect of these fibres on cell experiments is expected.

All scaffolds displayed a sharp increase in cell number after 7 days of culture. The minimum cell number was observed for BP-B, since the number of cells adhering initially was much lower than in the other scaffolds. However, this effect compensated itself in 2 weeks and the cell number became higher than in SP5 and SP10 scaffolds. This can be attributed the better interconnectivity of the pores and much proper mass transfer of the feeding medium in bioplotted scaffolds (BP-B and BP-O) compared to the ones prepared by salt-leaching. As emphasized previously, interconnection of pores is an important factor to support cell migration, cell proliferation and mass transfer. Increasing scaffold porosity will cause increased permeability. Lacroix and et al. (2013) demonstrated that inadequate porous structures resulted in limited circulation of the fluid within the scaffold, which lowered cell viability. Thus, high porosity and interconnectivity is necessary to allow an easy circulation of nutrients and growth factors.

In this study, the effects of scaffold porosity on osteoblastic cell proliferation and activity were investigated under static conditions. Our results demonstrated that cell proliferation and cellular activities were enhanced with increased scaffold permeability. After day 7, the rate of cell growth decreased because of expression of differentiation factors (van Griensven et al., 2005). On days 14 and 21, the number of cells demonstrated parallel relation to the pore size and interconnectivity.

\subsubsection{Mineralization by osteoblastic activity}

The ability of cells to produce mineralized matrix and calcium nodules is an indicator of bone formation in vitro. In the literature, mineralization is indicated in different ways, such as 'calcification', 'mineral deposition', 'calcium salts', 'mineralized matrix' and 'bone nodule formation'. There are several methods used for the detection of mineralization. These include von Kossa staining, haemotoxylin staining, EDX analysis, FTIR and X-ray diffraction, where the von Kossa staining method has been widely used to examine mineralization in vitro.

In this study, von Kossa staining for mineralization was positive for all scaffolds, with the most intense staining in bioplotted scaffolds (Figure 7A). After staining, calcium salts are coloured as dark brown or black nodules. Significant amounts of black-stained deposits were observed after 35 days of culture on 3D scaffolds, which indicates that seeded BMSCs differentiated into osteoblasts producing mineralized tissues. Light microscopy images showed that small nodules were formed on SP5, while some relatively larger nodules were observed beside small ones on SP10. von Kossa staining indicated more extensive mineralization of osteoblasts on bioplotted scaffolds. Black deposits covered all the surfaces of fibres on the upper and lower sides of bioplotted scaffolds, while no apparent positive staining was observed on unseeded controls. These results suggest that BMSCs were able to differentiate into the osteogenic lineage in vitro. This suggestion was further supported by SEM/EDX results. SEM/EDX analysis was performed in conjunction with von Kossa staining in order to confirm mineralization. Figure $7 \mathrm{~B}$ shows morphological observation of mineral deposition on salt-leached, spongy and bioplotted scaffolds. At the end of 5 weeks, it was noticeable that all constructs were covered with multilayers of cells, and cells started filling up the pores with extracellular matrix and abundant mineral deposits, indicating good cell attachment and proliferation of osteoblasts. SEM images demonstrated that extracellular mineral deposition was higher on bioplotted scaffolds than on salt-leached scaffolds, which was also confirmed by analysing the seeded scaffolds' surfaces via SEM/EDX imaging, which provides a determination of the chemical composition of material surfaces. The amount of elemental calcium (Ca) and phosphorus (P) was measured from the mineral nodules synthesized by osteoblasts on the surfaces of different scaffolds, and the weight percentages of elements measured on days 1 and 35 are shown in Table 2. It is known that calcium and phosphate serves as the nucleating agent for the formation of bone hydroxyapatite (HAp). EDX analysis demonstrates the presence of $\mathrm{Ca}$ and $\mathrm{P}$ on the surface of all scaffolds after 5 weeks of culture, while these elements were not detected on day 1 , since there was not yet any mineral deposition. EDX detected low levels of Ca and $\mathrm{P}$ deposition on salt-leached scaffolds compared to bioplotted scaffolds after 35 days of cultivation. Moreover, EDX analysis revealed that the Ca:P ratio of BP-O $(\sim 1.60)$ was close to the theoretical value of 1.67 attributed to HAp, whereas Ca: $\mathrm{P}$ ratios of SP5 and SP10 ( $\sim 0.55$ for both) were very low compared to that of HAp. It has been reported that a Ca:P ratio of $<1.0$ is not biomedically important, since the structure is not stable (Basu et al., 2009). These results indicate that higher mineralization on bioplotted scaffolds might result from stiffness of the matrix. It has been stated that substrate stiffness can influence the morphology and cellspecific protein expression.

\subsubsection{Effect of cell proliferation on compressive properties of $3 D$ PEU scaffolds}

The mechanical performances of BMSC-seeded 3D scaffolds were characterized under wet conditions after 1, 21 and 35 days of cultivation. In natural tissues, the ECM provides compressive strength to the tissues (Chan and Leong, 2008). Increase of compressive stiffness of scaffolds after in vitro cell culture is an indication of ECM deposition by proliferated cells. The compressive moduli of seeded scaffolds on days 1, 21 and 35 are 
(A)
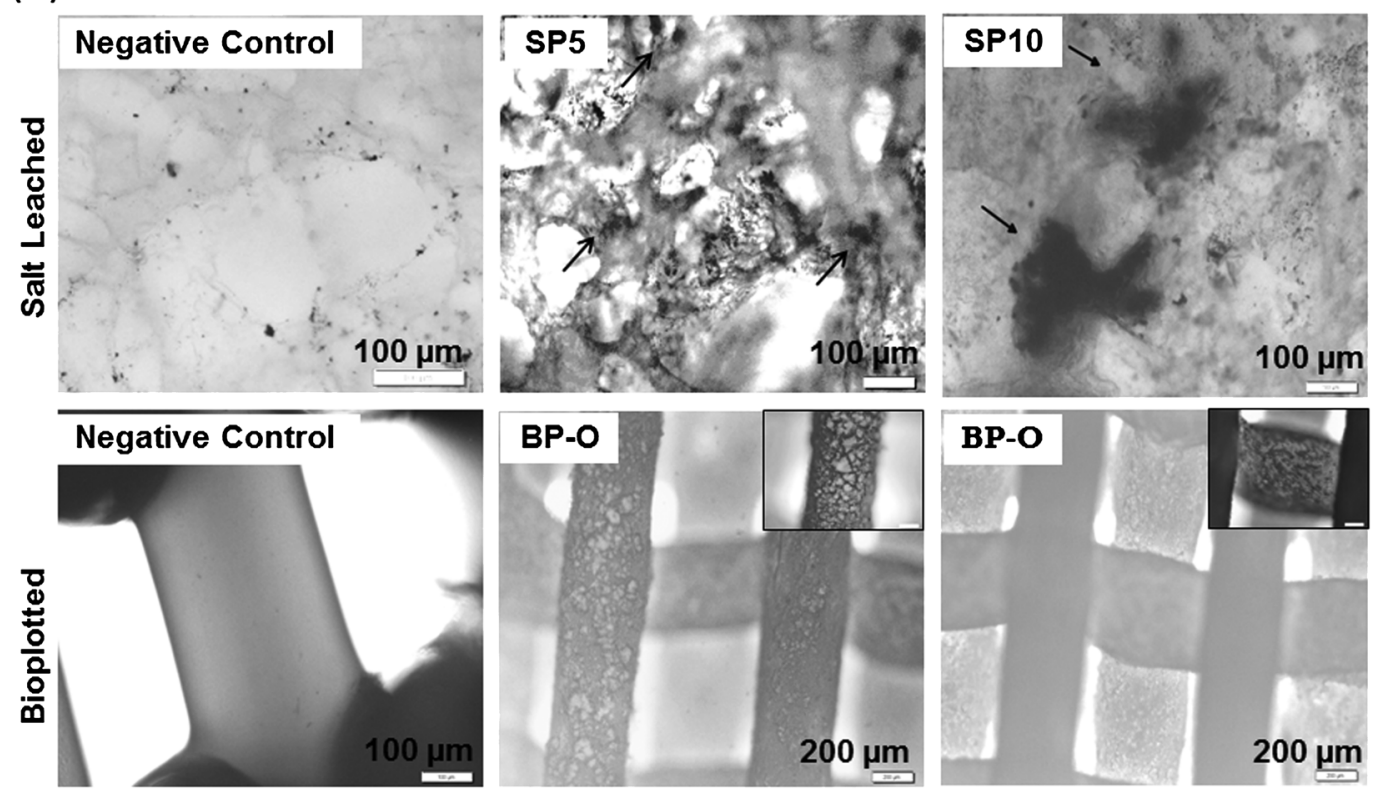

(B)
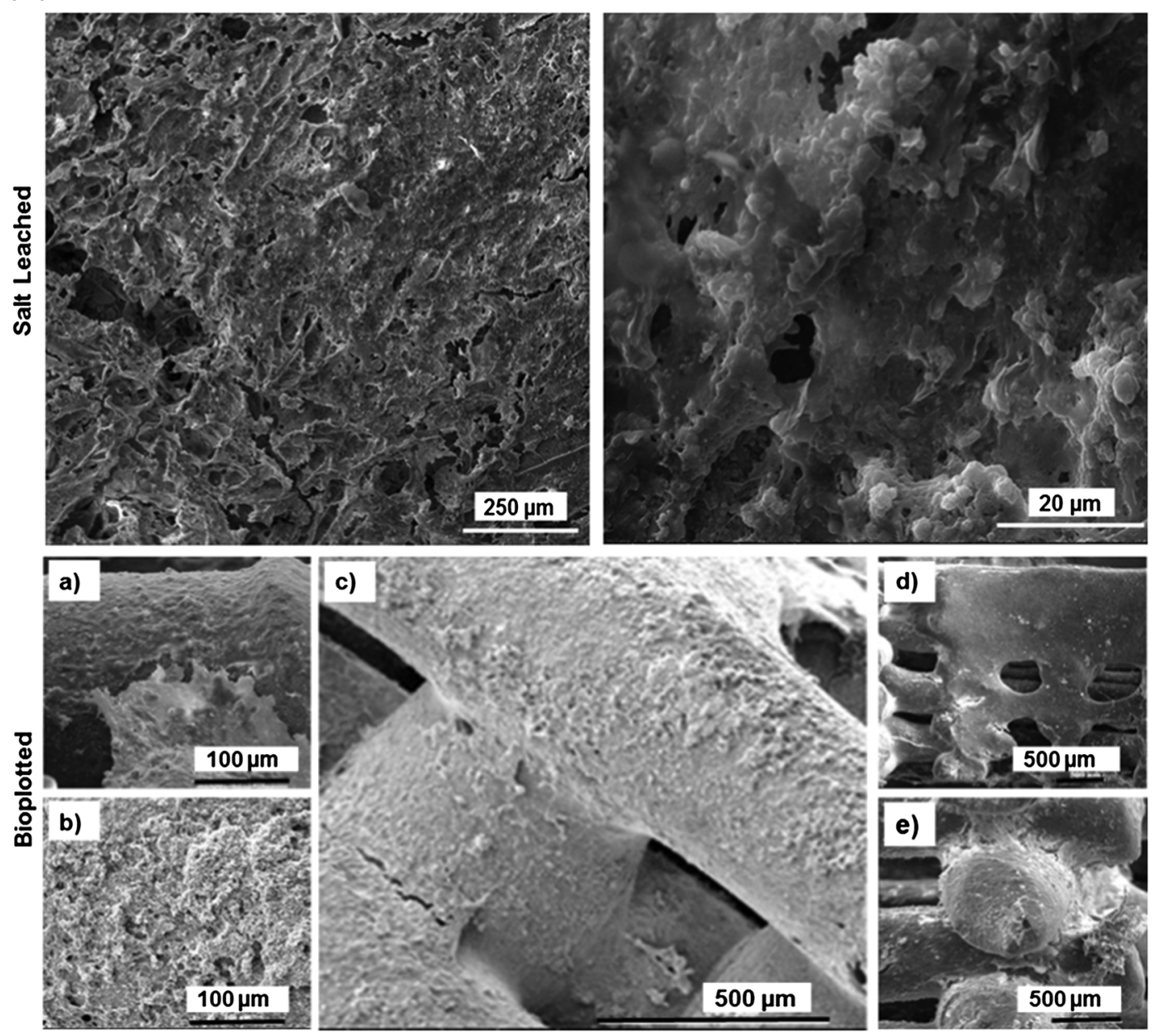

Figure 7. (A) von Kossa staining of mineral deposition on 3D scaffolds after 5 weeks of culture; (B) SEM images showing ECM deposition and mineralization on salt-leached and bioplotted scaffolds after 5 weeks of culture. Bioplotted: (a-c) top view; (d, e) side view

compared in Table 3. While the compressive modulus of SP5 increased from $25.6 \pm 3.83$ to $35.01 \pm 2.82 \mathrm{kPa}$, that of SP10 changed from $16.38 \pm 3.20$ to $25.01 \pm 4.21 \mathrm{kPa}$ after 21 days of cell culture. Moreover, the compressive moduli increased to $44.44 \pm 3.48$ and $37.40 \pm 3.94 \mathrm{kPa}$ for SP5 and SP10, respectively, with further cultivation 
Table 2. Weight percentage of elements on different scaffolds seeded with BMSCs

\begin{tabular}{|c|c|c|c|c|c|c|}
\hline \multirow[t]{2}{*}{ Element } & \multicolumn{2}{|c|}{ SP5 } & \multicolumn{2}{|c|}{ SP10 } & \multicolumn{2}{|c|}{ BP-O } \\
\hline & Day 1 & Day 35 & Day 1 & Day 35 & Day 1 & Day 35 \\
\hline C & 71.59 & 49.54 & 62.30 & 49.11 & 67.86 & 38.23 \\
\hline 0 & 28.41 & 39.62 & 37.47 & 31.66 & 31.81 & 33.64 \\
\hline$P$ & 0.00 & 6.95 & 0.00 & 12.36 & 0.00 & 10.83 \\
\hline $\mathrm{Ca}$ & 0.00 & 3.89 & 0.23 & 6.87 & 0.33 & 17.31 \\
\hline
\end{tabular}

Table 3. Variations in compressive moduli of seeded 3D scaffolds by time

\begin{tabular}{lccc}
\hline Sample & \multicolumn{3}{c}{$E(\mathrm{kPa})$} \\
\cline { 2 - 4 } & Day 1 & Day 21 & Day 35 \\
\hline SP5 & $25.6 \pm 3.83$ & $35.01 \pm 2.82$ & $44.44 \pm 3.48$ \\
SP10 & $16.38 \pm 3.20$ & $25.01 \pm 4.21$ & $37.40 \pm 3.94$ \\
BP-B & $4610 \pm 520$ & - & $5095 \pm 614$ \\
BP-O & $3535 \pm 437$ & - & $3893 \pm 382$ \\
\hline
\end{tabular}

up to 35 days. Compressive moduli increased by $36 \%$ and $73 \%$ for SP5 and by 53\% and 98\% for SP10 after 21 and 35 days of cultivation, respectively. The higher increase in the mechanical properties of SP10 was most probably due to its more porous structure compared to SP5, and this might have resulted in a higher cell penetration and proliferation of cells throughout the scaffold and thus a larger amount of ECM deposition after cell culture. This is in agreement with the literature result reported that chondrocytes seeded in gelatin scaffolds with higher pore size showed higher compression strength after cell culture compared to scaffolds with smaller pore size (Lien et al., 2010). For bioplotted ones, after 35 days of cultivation, the compressive moduli of BP-B and BP-O increased from $4610 \pm 520 \mathrm{kPa}$ (day 1) to $5095 \pm 614 \mathrm{kPa}$ (day 35) and from $3535 \pm 437 \mathrm{kPa}$ (day 1) to $3893 \pm 382 \mathrm{kPa}$ (day 35) for BP-B and BP-O, respectively. For both BP-B and BP-O scaffolds, the increase was approximately $10 \%$. As seen from these results, the percentage increase in compressive strength after cell culture was more remarkable in salt-leached scaffolds than in bioplotted ones. This is because there is a big difference between the initial stiffness of salt-leached scaffolds and bioplotted ones. However, when total increase was taken into consideration, it is obvious that the increase in compressive strength was much higher on bioplotted scaffolds. It is not valid to evaluate the efficacy of osseous tissue ingrowth by taking the initial mechanical property as the only criterion. For example, it has been demonstrated that biphasic calcium phosphate ceramics (BCPs) with low microporosity and high mechanical strength showed low bioresorption and bioactivity after implantation, while BCPs with initially higher microporosity and lower mechanical strength revealed a two- or three-fold increase in mechanical strength after implantation. The researchers indicated that highly macroporous BCPs promoted higher ECM deposition in vivo and better integration with the native tissue (Trécant et al., 1994).

\section{Conclusion}

In the present study, various macroporous 3D structures were obtained from lysine-based poly(ester-urethane) by using bioplotting and salt-leaching techniques, and their mechanical and thermal properties and their abilities to promote osteogenesis of BMSCs were compared. Alamar blue cell viability tests showed that all scaffolds allowed cellular attachment, proliferation and osteogenic differentiation. Due to their higher pore size and interconnectivity, the cell proliferation rate was higher on bioplotted scaffolds than on salt-leached ones. Among the salt-leached scaffolds, constructs with higher porosity (96\%) demonstrated better proliferation compared to constructs with lower porosity (85\%). This can be explained by the presence of larger pores and higher pore interconnectivity. According to SEM images, the cells cultured on all 3D scaffolds had good cell proliferation and efficiently mineralized extracellular matrix (ECM). von Kossa staining results indicated that calcium deposition was more abundant on bioplotted scaffolds than on saltleached constructs. EDX results further supported the von Kossa staining of mineralization by qualitative and quantitative analysis of calcium and phosphate expression, with the highest calcium concentration measured on bioplotted scaffolds. It was concluded that the substrate stiffness of bioplotted scaffolds as well as pore size and interconnectivity enhanced the osteogenic activity. As a result, among the various PEU scaffolds prepared in this study, bioplotted BP-O scaffolds in particular possess great potential for nonload bearing bone tissue engineering applications. Scaffolds prepared by salt-leaching showed less cell proliferation and differentiation, since the pores and interconnectivities were less. However, they can be used as soft tissue scaffolds since they have the property of biodegradability and the size and interconnectivity will be better in biological media because of enzymatic effects.

\section{Conflict of interest}

The authors have declared that there is no conflict of interest.

\section{Acknowledgements}

This work was supported by the European FP6 NoE EXPERTISSUES project (Grant No. NMP3-500283), the mini-project Fibrocell, TUBITAK (Grant No. TBAG 105 T508 Nanobiomat) and by METU-BAP. 


\section{References}

Aksoy EA, Motta A, Fedel M et al. 2008; Plasma protein adsorption and platelet adhesion on heparin-immobilized polyurethane films. $J$ Bioact Compat Pol 23: 505-519.

Basu B, Katti D, Kumar A. 2009; Advanced Biomaterials: Fundamentals, Processing, and Applications. Wiley: New Jersey, NJ, USA.

Bennett BT. 1994; Regulation and requirements. In Essentials for Animal Research: A Primer for Research Personnel, 2nd edn, Bennett BT, Brown MJ, Schofield JC (eds). National Agricultural Library: Beltsville, MD; 1-9.

Burke A, Hasirci N. 2004; Polyurethanes in biomedical applications. In Biomaterials: From Molecules to Engineered Tissues, Hasirci N, Hasirci V. (eds). Kluwer Academic/Plenum: New York.

Calil M, Gaboardi F, Bardi M et al. 2007; Enzymatic degradation of poly $(\varepsilon$ caprolactone) and cellulose acetate blends by lipase and $\alpha$-amylase. Polym Test 26(2): 257-261.

Chan BP, Leong KW. 2008; Scaffolding in tissue engineering: general approaches and tissue-specific considerations. Eur Spine J 17(4): 467-479.

Diba M, Fathi MH, Kharaziha M. 2011; Novel forsterite/polycaprolactone nanocomposite scaffold for tissue engineering applications. Mater Lett 65(12): 1931-1934.

Discher DE, Janmey P, Wang YL. 2005; Tissue cells feel and respond to the stiffness of their substrate. Science 310: 1139-1143.

Engler A, Bacakova L, Newman C et al. 2004; Substrate compliance versus ligand density in cell on gel responses. Biophys $J \mathbf{8 6}$ (1): 617-628.

Flanagan LA, Ju YE, Marg B et al. 2002; Neurite branching on deformable substrates. NeuroReport 13(18): 2411-2415.

Gan Z, Yu D, Zhong Z et al. 1999; Enzymatic degradation of poly( $\varepsilon$-caprolactone)/poly (DL-lactide) blends in phosphate buffer solution. Polymer 40(10): 2859-2862.

Harley BA, Leung JH, Silva EC et al. 2007; Mechanical characterization of collagenglycosaminoglycan scaffolds. Acta Biomater 3(4): 463-474.

Hasirci N, Aksoy EA. 2007; Synthesis and modifications of polyurethanes for biomedical purposes. High Perform Polym 19: 621-637.

Hasirci N. 1991; Polyurethanes. In High Performance Biomaterials: Comprehensive Guide to Medical and Pharmaceutical Application, Szycher M (ed.). Technomic Publishing: Lancaster, UK.

Hasirci V, Tezcaner A, Hasirci N et al. 2003; Oxygen plasma modification of poly (3-hydroxybutyrate-co-3-hydroxyvalerate) film surfaces for tissue engineering purposes. J Appl Polym Sci 87: 1285-1289.

Hench LL. 1991; Bioceramics: from concept to clinic. J Am Ceram Soc 74: 1487-1510.
Hing KA. 2005; Bioceramic bone graft substitutes: influence of porosity and chemistry. Int $J$ Appl Ceram Technol 199: 184-199.

Hollis JM, Flahiff CM. 1995; Factors affecting bone ingrowth. Encyclop Handb Biomater Bioeng 1: 799-821.

Hong SG, Lin YC, Lin CH. 2008; Crystallization and degradation behaviors of treated polyhydroxybutyrates. React Funct Polym 68: 1516-1523.

Joshi VS, Lei NY, Walthers CM, Wu B, Dunn JCY. 2013; Macroporosity enhances vascularization of electrospun scaffolds. $J$ Surg Res 183: 18-26.

Kasper FK, Liao J, Kretlow JD et al. 2008; Flow perfusion culture of mesenchymal stem cells for bone tissue engineering. In Stem Book. Stem Cell Research Community: StemBook, DOI/10.3824/stembook.1.18.1: http://www. stembook.org

Kayirhan N, Denizli A, Hasirci N. 2001; Adsorption of blood proteins on glowdischarge modified polyurethane membranes. J Appl Polym Sci 81: 1322-1332.

Keogh MB, O’Brien FJ, Daly JS. 2010; Substrate stiffness and contractile behaviour modulate the functional maturation of osteoblasts on a collagen-GAG scaffold. Acta Biomater 6: 4305-4313.

Kim K, Yeatts A, Dean D et al. 2010; Stereolithographic bone scaffold design parameters: osteogenic differentiation and signal expression. Tissue Eng B Rev 16: 523-539.

Kiziltay A, Fernandez AM, San Roman J et al. 2012; Lysine based poly(ester-urethane) films for tissue engineering applications. $J$ Biomater Tissue Eng 2: 1-10.

Kutay S, Tincer T, Hasirci N. 1990; Polyurethanes as biomedical materials. $\mathrm{Br}$ Polym J 23: 267-272.

Lacroix J, Jallot E, Nedelec JM, Lao J. 2013; Influence of glass scaffolds macroporosity on the bioactive process. $J$ Phys Chem $B$ 117: $510-517$.

Lien SM, Ko LY, Huang TJ. 2010; Effect of crosslinking temperature on compression strength of gelatin scaffold for articular cartilage tissue engineering. Mater Sci Eng 30: 631-635.

Mistry MA, Mikos AG. 2005; Tissue engineering strategies for bone regeneration. $A d v$ Biochem Eng Biotechnol 94: 1-22.

Mandal BB, Gil ES, Panilaitis B et al. 2013; Laminar silk scaffolds for aligned tissue fabrication. Macromol Biosci 13(1): 48-58.

Mandal BB, Kundu SC. 2009; Cell proliferation and migration in silk fibroin 3D scaffolds. Biomaterials 30: 2956-2965.

Marcos-Fernández A, Abraham GA, Valentín JL et al. 2006; Synthesis and characterization of biodegradable non-toxic poly (ester-urethane-urea)s based on poly ( $\varepsilon$-caprolactone) and amino acid derivatives. Polymer 47(3): 785-798.
Mitsak AG, Kemppainen JM, Harris MT 2011; Effect of polycaprolactone scaffold permeability on bone regeneration in vivo. Tissue Eng A 17: 1831-1839.

Nelson CE, Gupta MK, Adolph EJ et al. 2012; Sustained local delivery of siRNA from an injectable scaffold. Biomaterials 33: 1154-1161.

Ozdemir Y, Serbetci K, Hasirci N. 2002; Oxygen plasma modification of polyurethane membranes. J Mater Sci Mater Meth 13: 1147-1152.

Pek YS, Wan ACA, Ying JY. 2010; The effect of matrix stiffness on mesenchymal stem cell differentiation in a 3D thixotropic gel. Biomaterials 31: 385-391.

Pelham RJ, Wang YL. 1997; Cell locomotion and focal adhesions are regulated by substrate flexibility. Cell Biol 94: 13661-13665.

Rada T, Santos TC, Marques AP et al. 2012; Osteogenic differentiation of two distinct subpopulations of human adipose-derived stem cells: an in vitro and in vivo study. $J$ Tissue Eng Regen Med 6: 1-11.

Sharaf B, Faris CB, Abukawa H et al. 2012; Three-dimensionally printed polycaprolactone and $\beta$-tricalcium phosphate scaffolds for bone tissue engineering: an in vitro study. $J$ Oral Maxil Surg 70: 647-656.

Standard guide for assessing microstructure of polymeric scaffolds for use in tissue engineered medical products. 2010 ASTM F2450-10.

Trécant M, Delécrin J, Royer J. 1994; Mechanical changes in macro-porous calcium phosphate ceramics after implantation in bone. Clin Mater 15: 233-240.

Ulubayram K, Hasirci N. 1992; Polyurethanes: effect of chemical composition on mechanical properties and oxygen permeability. Polymer 33: 2084-2088.

van Griensven M, Diederichs S, Kasper C. 2005; Mechanical strain of bone marrow stromal cells induces proliferation and differentiation into osteoblast-like cells. In Topics in Tissue Engineering, Ashammakh NA, Reis RL (eds). http://www.oulu.fi/ spareparts/ebook topics in $\mathrm{t}$ e vol2/abstracts/griensven_0102.pdf.

Wagoner J, Harley A, Brendan AC. 2011 Mechanobiology of Cell-Cell and Cell-Matrix Interactions. Springer: New York.

Yilgor P, Sousa R, Reis RL et al. 2008; 3D plotted PCL scaffolds for stem cell based bone tissue engineering. Macromol Symp 269: 92-99.

Yilgor P, Sousa RA, Reis RL et al. 2010; Effect of scaffold architecture and BMP2 BMP7 delivery on in vitro bone regeneration. J Mater Sci Mater Meth 21(11): 2999-3008.

Zhang J, Zhang H, Wu L et al. 2006; Fabrication of three-dimensional polymeric scaffolds. J Mater Sci 1: 1725-1731. 